\title{
GPS observations of PW during the passage of a typhoon
}

\author{
Yuei-An Liou and Cheng-Yung Huang \\ Center for Space and Remote Sensing Research, and Institute of Space Sciences, National Central University, Chungli, Taiwan
}

(Received December 6, 1999; Revised May 25, 2000; Accepted May 31, 2000)

\begin{abstract}
The Global Positioning System (GPS) is used to provide hourly measurements of precipitable water (PW) in Taiwan during the passage of tropical cyclones. Typhoon Zeb, which caused serious damage in the Philippines, Taiwan, and Japan in mid-October 1998, is used as an example in this paper. GPS data are analyzed from the Central Weather Bureau's (CWB's) three weather stations in Taiwan, and from a site in Tsukuba, Japan. Bernese version 4.0 software is utilized to solve GPS signals for total delay due to the neutral atmosphere at the three CWB sites. Wet delay is obtained by subtracting surface pressure derived dry delay from total delay. Wet delay is then converted to PW through a simple calculation. GPS-observed PW time series demonstrate that PW is, in general, high before and during the occurrence of the typhoon, and low after the typhoon. PW increased from about $5 \mathrm{~cm}$ on DoY 285 (October 13) to near $8 \mathrm{~cm}$ or so on DoY 288 (October 16) when the typhoon was striking Taiwan, and, then, decreased to 2-3 cm after passage of the typhoon. In addition, GPS-observed PW depletion from $8 \mathrm{~cm}$ on DoY 288 to about $3 \mathrm{~cm}$ on DoY 290 is found to be consistent with radiosonde observations acquired at the Taipei weather station.
\end{abstract}

\section{Introduction}

Tropical cyclones are the most serious weather systems that threaten Taiwan. Accurate prediction of their track, intensity, precipitation, and wind fields is extremely crucial to reduce their damages to agriculture, industry, and human life. Of the devastating tropical cyclones, typhoon Zeb that caused serious damage in Taiwan in mid-October 1998 was a typical example. It took 39 lives, destroyed 30 buildings, and caused agricultural loss of $\$ 170$ million (U.S.).

Since atmospheric water vapor is the source of precipitation, and a dominant constituent of the energy source to maintain the dynamics of the cyclones, knowledge of its spatial and temporal distribution through continuous GPS observations of precipitable water (PW) is valuable in the study, monitoring and prediction of tropical cyclones. The authors have monitored PW during the past several years using microwave radiometry, GPS and radiosondes. We began monitoring PW using microwave radiometry (Liou, 1999; Liou and Chang, 2000). The radiometric approach was then applied to constrain GPS baseline solutions to provide absolute sensing of PW at a variety of remote GPS sites (Liou and Yang, 1999). Recently, the GPS sensing technique was advanced to estimate absolute total wet delay that is subsequently converted to PW (Liou et al., 2000a). We showed that GPS and radiometric measurements of PW agree to better than $94 \%$, and that the disagreement between the two methods scales with PW. GPS measurements of PW have also been demonstrated by Rocken et al. (1993, 1995, 1997), Bevis et al. (1992, 1994), Businger et al. (1996) and Tregoning et al. (1998).

Copy right (C) The Society of Geomagnetism and Earth, Planetary and Space Sciences (SGEPSS); The Seismological Society of Japan; The Volcanological Society of Japan; The Geodetic Society of Japan; The Japanese Society for Planetary Sciences.
In this paper, we apply the GPS sensing technique to monitor PW depletion after the passage of tropical cyclones. Typhoon Zeb (1998) is chosen as a case study. The relationship between zenith wet delay (ZWD) and PW is presented in the following section. GPS observation of PW depletion after Typhoon Zeb is subsequently presented.

\section{Zenith Wet Delay and Precipitable Water}

Microwave signals transmitted by GPS satellites are delayed by the neutral atmosphere. The total delay can be used to derive the wet delay due to PW by subtracting the hydrostatic delay from it. That is, the wet component can be converted to PW through (Bevis et al., 1994)

$$
\mathrm{PW}=\Pi \times \mathrm{ZWD},
$$

where

$$
\Pi=\frac{10^{8}}{\rho R_{\mathrm{v}}\left[\left(k_{3} / T_{\mathrm{m}}\right)+k_{2}^{\prime}\right]},
$$

and $\rho$ is the density of water $\left(\mathrm{kg} / \mathrm{m}^{3}\right), R_{\mathrm{v}}$ is the specific gas constant of water vapor $(\mathrm{J} / \mathrm{kg}-\mathrm{K}), k_{2}^{\prime}$ is $22.1 \pm 2.2(\mathrm{~K} / \mathrm{mb}), k_{3}$ is $(3.739 \pm 0.012) \times 10^{5}\left(\mathrm{~K}^{2} / \mathrm{mb}\right), T_{\mathrm{m}}$ is the weighted mean temperature of the atmosphere $(\mathrm{K})$,

$$
T_{\mathrm{m}}=\frac{\int\left(P_{\mathrm{v}} / T\right) d z}{\int\left(P_{\mathrm{v}} / T^{2}\right) d z}
$$

where $P_{\mathrm{v}}$ is the pressure of water vapor $(\mathrm{mb})$, and $T$ is the temperature of the atmosphere $(\mathrm{K})$. Following the Liou et al. (2000b) approach we compute $\Pi$ based on radiosonde observations collected at the Taipei site each October from the year 1988 to 1997 . It was found that $\Pi$ ranges from 0.158 to 0.167 , with an average value of 0.162 and a standard deviation of 0.0014 . These statistics about $\Pi$ for October show expected difference by about $+2 \%$ from those for March 
given by Liou et al. (2000b). The difference indicates that $\Pi$ is seasonally dependent (Bevis et al., 1994).

Since there are no appropriate data to provide high frequency measurements of the atmospheric profiles for the estimate of $T_{\mathrm{m}}$, Bevis et al. (1992) suggested that $T_{\mathrm{m}}$ can be approximated by the surface temperature $T_{\mathrm{s}}$. Based on radiosonde soundings observed at the Taipei site each October from the year 1988 to 1997 , we determine the relationship between $T_{\mathrm{m}}$ and $T_{\mathrm{s}}$ by minimizing the Chi-square error statistic as

$$
T_{\mathrm{m}}=0.9501 T_{\mathrm{s}}-2.6185 .
$$

The root mean square (rms) deviation about this regression is $1.36 \mathrm{~K}$. The corresponding bias is $-0.28 \mathrm{~K}$. Equation (4) differs from a similar relationship from Liou et al. (2000b), $T_{\mathrm{m}}=1.07 T_{\mathrm{s}}-31.5$ with a corresponding rms deviation of $1.67 \mathrm{~K}$, using radiosonde data collected at the Taipei site each March from the year 1988 to 1997. In addition, it differs from another similar relationship from Bevis et al. (1992), $T_{\mathrm{m}}=$ $0.72 T_{\mathrm{s}}+70.2$ with a corresponding rms deviation of $4.74 \mathrm{~K}$, using radiosonde data obtained over a 2-year interval from 13 stations in the United States. It is readily justified that $\Pi$ is site dependent (Bevis et al., 1994). Note that Eq (4) is applied to derive $T_{\mathrm{m}}$ from $T_{\mathrm{s}}$ for the other two CWB stations because no radiosonde data are available at those sites. It is expected that this adoption will not cause significant influence to GPS solutions since three CWB sites of interest are located on the Taiwan Island with spacing less than $320 \mathrm{~km}$.

We estimate hourly ZWD at the three CWB stations together with the baseline component from Tsukuba to the three CWB sites by using the Bernese GPS software version 4.0 developed by the University of Berne (Beutler et al., 1996). L1 and L2 carrier phase observations are used in data reduction, and the precise GPS ephemeris is obtained from the International GPS Service. A satellite elevation cutoff angle of 10 degrees is used in the data processing. A threshold of $1 \mathrm{~cm}$ in the total delay (TD) solution standard deviation is set to assure good quality in GPS estimates of ZWD. The Tsukuba GPS station is chosen as reference because a minimum baseline of $1,500 \mathrm{~km}$ or so is required to de-correlate atmospheric effects on the two ends of the baseline (Liou et al., 2000b). Previously, Rocken et al. (1993) suggested that the requirement for the minimum baseline should be at least $500 \mathrm{~km}$, while Tregoning et al. (1998) recommended 2,000 km. Rocken et al. (1993) stated that GPS satellite elevation angles are nearly identical at both ends of short baselines, and thus the ZWD parameters for the two ends are highly correlated. Note that all of the baselines between Tsukuba and the three CWB sites are longer than $2,000 \mathrm{~km}$.

\section{Observed PW Depletion after 1998 Typhoon Zeb}

Figure 1 shows the track of 1998 Typhoon Zeb and the geographic locations of the three CWB GPS sites used in this study. Included are the southernmost site of henc (HenChung), the central site of chia (Chia-Yi), and the northernmost site of banc (Taipei). Zeb was moving northeastern with its eye at $24.5^{\circ} \mathrm{N}, 122.5^{\circ} \mathrm{E}$ about $100 \mathrm{~km}$ east of Taiwan at 1100 LST (local standard time) on October 16, 1998. Its movement is almost parallel to the long axis of Taiwan Island with a speed of about $20 \mathrm{~km} / \mathrm{hr}$.

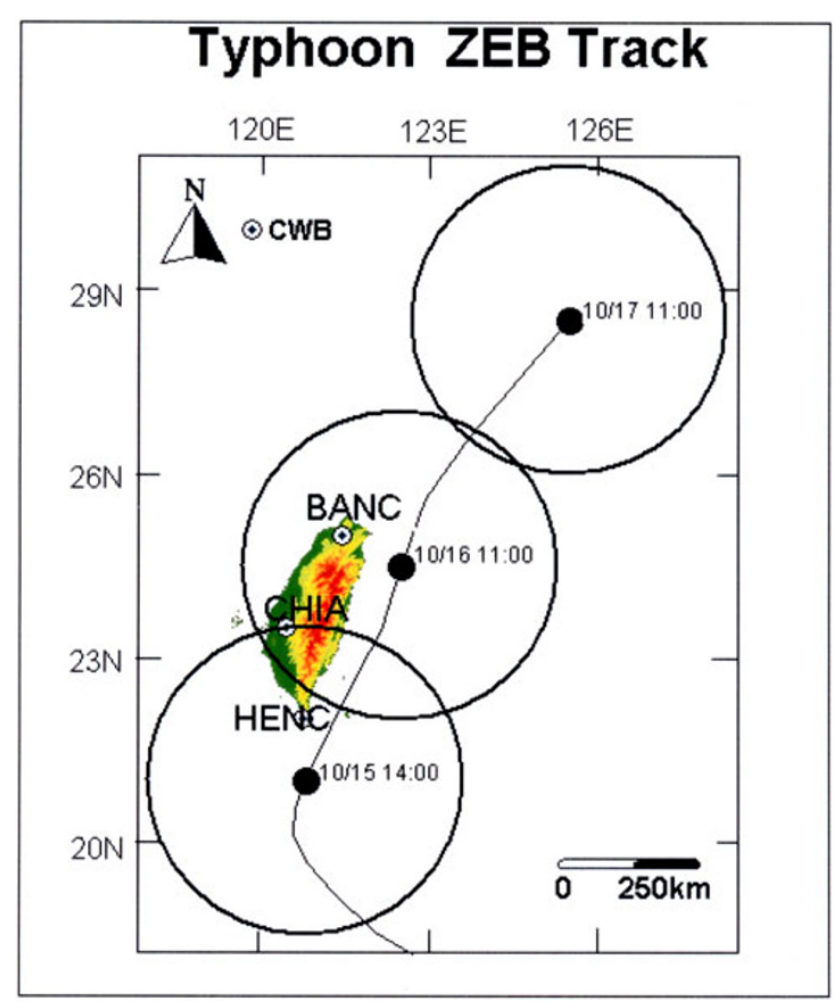

Fig. 1. Track of 1998 Typhoon Zeb, and the geographic locations of the three CWB sites, henc (Hen-Chung), chia (Chia-Yi), and banc (Taipei). Circles indicate the regions that are under threat from Zeb.
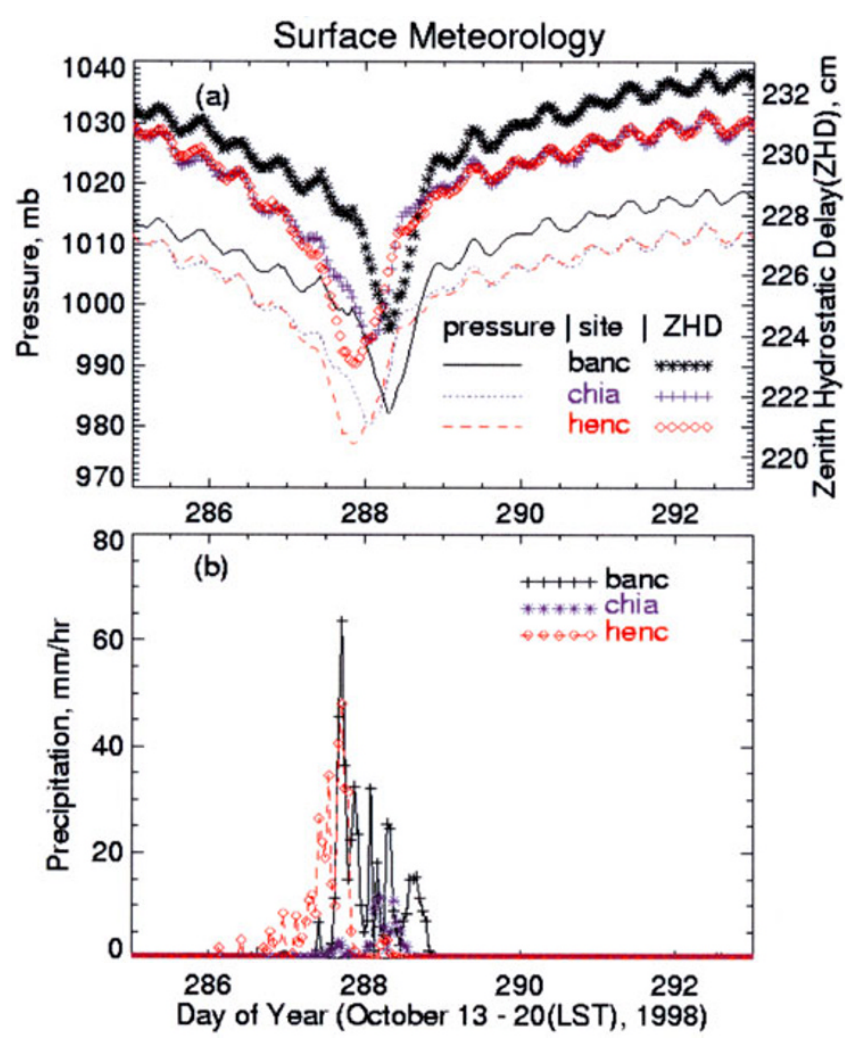

Fig. 2. Measurements of (a) surface pressure and ZHD estimated from surface pressure, and (b) precipitation collected at three sites in Taiwan from LST DoY 285 (October 13) to 292 (October 20), 1998. 


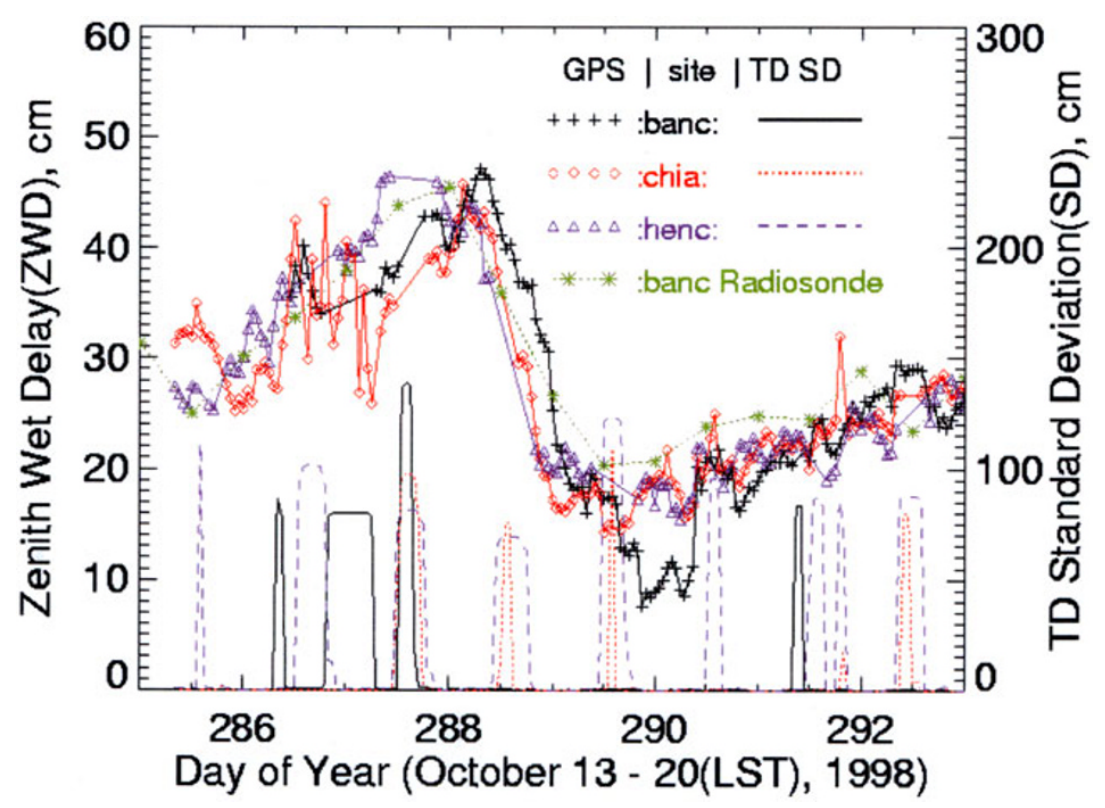

Fig. 3. GPS observed ZWD and its solution standard deviation at the three CWB sites, and radiosonde observations of ZWD at the Taipei site from LST October 13 to $20,1998$.

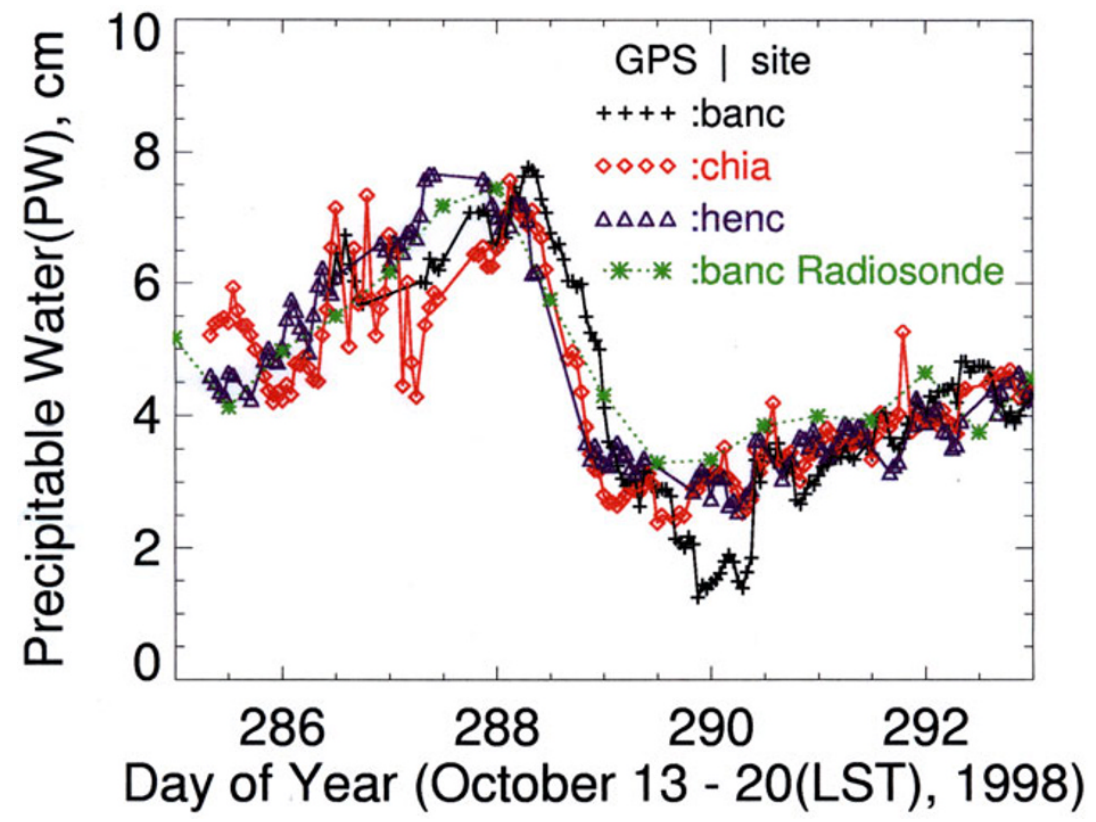

Fig. 4. GPS observed PW at the three CWB sites and radiosonde measurements of PW at the Taipei site from LST October 13 to 20, 1998.

Figure 2 shows the surface measurements of (a) pressure and ZHD estimated from surface pressure, and (b) precipitation collected at the three sites of interest in Taiwan from DoY 285 (October 13) to 292 (October 20), 1998. From the pressure curves, it is evident that the center of the Typhoon Zeb passed Taiwan between DoY 287 and 289 when the dips of the pressure curves occur. About the same period of time, heavy rainfall generated by the typhoon occurs at all sites. The pressure dips in the time series occur sequentially at henc, chia and banc. The sequence is consistent with the northward path of the Typhoon Zeb.
Figure 3 shows GPS observed ZWD and TD solution standard deviation at the three CWB sites, and radiosonde observations of ZWD at the Taipei site from October 13 to 20, 1998. The radiosonde launching site and the GPS site are only $\sim 10$ meters apart. Specifications of radiosondes and surface meteorological sensors, and their instrumental uncertainties have been discussed by Liou et al. (2000b). Hence, they are not repeated here. It is an observable general trend that ZWD starts to increase before the typhoon, reaches its maximum during the closest approach of the typhoon, decreases to a minimum immediately after its passage, and 
finally recovers to its nominal value a few days later. We note that the quality of GPS solutions is poor for some periods of time. Hence, quality control (QC) must be performed to assure good quality of ZWD solutions from GPS. The solutions are defined as poor if the TD solution standard deviation is relatively large. Note that it has been suggested that the accuracy of GPS observed PW possibly scales with total water burden (Liou et al., 2000a). Latter, the scaling issue is further demonstrated by Liou et al. (2000b). In addition, the atmosphere could be extremely inhomogeneous when a typhoon is nearby. We also note that cycle slips occurred periodically, often within 2 hours after midday, as shown in the solution standard deviations in Figure 3. The periodic cycle slips could be caused by combined effects of path delays in the wet troposphere associated with the typhoon and in the ionosphere associated with local noon. Furthermore, weak semi-diurnal variations that reflect climatological characteristics of the region are only observable when the influence of Zeb is weaker.

To acquire good quality in GPS estimates of ZWD, a threshold of $1 \mathrm{~cm}$ in the standard deviation is set when TD is determined. The resulting solutions of ZWD are then converted to PW. Figure 4 presents GPS observed PW at the three CWB sites and radiosonde measurements of PW at the Taipei site from October 13 to 20, 1998. Three major characteristics can be seen. First, PW signatures show an expected trend that correlates with ZWD. Second, the sequence of PW depletion occurs from south to north. The time lag in PW depletion between the southernmost (henc) and northernmost (banc) sites correlates with the northward movement of Zeb. Third, GPS and radiosonde observed PW generally agree. Both measurements increase from $5 \mathrm{~cm}$ on DoY 285 to $7-8 \mathrm{~cm}$ on DoY 288. Then, they decrease to the minimum on DoY 290, although the minimum is $3.5 \mathrm{~cm}$ for radiosondes observations and $2 \mathrm{~cm}$ for GPS measurements at banc. Finally, the PW observations return to their nominal values of $5 \mathrm{~cm}$ on DoY 292. We attribute at least part of the large discrepancy between the GPS and radiosonde PW measurements near the dip at banc to the inhomogeneity of the atmosphere.

\section{Concluding Remarks}

GPS is used to monitor PW in Taiwan during the passage of Typhoon Zeb in mid-October 1998. In general, the observed PW is high before and during the passage of a typhoon, and then decreases rapidly right after the passage of the center of the typhoon, and finally recovers to its nominal values a few days later. In particular for Typhoon Zeb, PW increased from about $5 \mathrm{~cm}$ on DoY 285 (October 13) to near $8 \mathrm{~cm}$ on DoY 288 (October 16) when the typhoon made its closest approach, and then decreased to $2-3 \mathrm{~cm}$ after its passage. The hourly GPS measurements of PW agree with PW derived twice daily from radiosonde observations at the Taipei site, including a decrease from $8 \mathrm{~cm}$ on DoY 288 to about $3 \mathrm{~cm}$ on DoY 290.

Acknowledgments. This work was supported in part by grants from NSC 87-NSPO(A)-PC-FA07-05 and ONR N00014-00-10528. They also thank CWB for providing GPS data, and Dr. Randolph Ware for technical advice.

\section{References}

Beutler, G., E. Brockman, S. Frankhauser, W. Gurtner, J. Johnson, L. Mervart, M. Rothacher, S. Schaer, T. Springer, and R. Weber, Bernese GPS Software Version 4.0. Univ. of Berne, 418 pp., 1996.

Bevis, M., S. Businger, T. A. Herring, C. Rocken, R. A. Anthes, and R. H. Ware, GPS meteorology: Remote sensing of atmospheric water vapor using the global positioning system, J. Geophys. Res., 97, 15,784-15,801, 1992.

Bevis, M., S. Businger, S. Chiswell, T. A. Herring, R. A. Anthes, C. Rocken, and R. H. Ware, GPS meteorology: Mapping zenith wet delays onto precipitable water, J. Appl. Meteoro., 33, 379-386, 1994.

Businger, S., S. R. Chiswell, M. Bevis, J. Duan, R. A. Anthes, C. Rocken, R. H. Ware, M. Exner, T. VanHove, and F. S. Solheim, The promise of GPS in atmospheric monitoring, Bull. Amer. Meteoro. Soc., 77, 5-18, 1996.

Liou, Y.-A., Ground-based radiometric sensing of atmospheric dynamics in precipitable water vapor, Atmospheric Sciences, 27, 141-158, 1999 (in Chinese).

Liou, Y.-A. and C.-L. Chang, Ground-Based Dual-Channel Radiometric Sensing of Water Vapor and Temperature Profiles, Atmospheric Sciences, 28(1), 17-26, 2000 (in Chinese)

Liou, Y.-A. and M. Yang, Precipitable water from GPS: A WVR constraint approach, Atmospheric Sciences, 27, 131-140, 1999 (in Chinese).

Liou, Y.-A., C.-Y. Huang, and Y.-T. Teng, Precipitable water observed by ground-based GPS receivers, Earth Planets Space, 52, 445-450, 2000a.

Liou, Y.-A., Y.-T. Teng, T. VanHove, and J. Liljegren, Comparison of precipitable water observations in the tropics by GPS, radiometer, and radiosondes, J. Appl. Meteoro., 2000b (in press).

Rocken, C., R. H. Ware, T. VanHove, F. Solheim, C. Alber, J. Johnson, M. Bevis, and S. Businger, Sensing atmospheric water vapor with the Global Positioning System, Geophys. Res. Lett., 20, 2,631-2,634, 1993.

Rocken, C., T. VanHove, J. Johnson, F. Solheim, R. H. Ware, M. Bevis, S. Businger, and S. Chiswell, GPS Storm-GPS Sensing of Atmospheric Water Vapor for Meteorology, J. Ocean. Atmos. Tech., 12, 468-478, 1995

Rocken, C., T. Van Hove, and R. H. Ware, Near real-time GPS sensing of atmospheric water vapor, Geophys. Res. Lett., 24, 3,221-3,224, 1997.

Tregoning, P., R. Boers, D. O'Brien, and M. Hendy, Accuracy of absolute precipitable water vapor estimates from GPS observations, J. Geophys. Res., 103, 28,701-28,710, 1998 .

Y.-A. Liou (e-mail: yueian@csrsr.ncu.edu.tw) and C.-Y. Huang 